[Agr. Biol. Chem., Vol. 36, No. 5, p. 703 710, 1972]

\title{
Investigations on the Influence of a Low Casein Diet on the Free Fatty Acids in Liver Homogenate by a Method with Some Devices in Purification Procedure Using $\mathrm{KOH}$
}

\author{
By Naoko Harada, Tei Sato and Fusae Takakura \\ Chukyo Women's University, Ohbu, Aichi-ken \\ Received July 30, 1971
}

\begin{abstract}
Previously, some changes were noticed in energy metabolism of rats fed a low casein diet. In connection with these phenomena, infuence of a low casein diet on the composition and amounts of free fatty acids in liver homogenate after autolyzing for a few hours was investigated. For the measurement of free fatty acids, they were purified by a method with some devices in purification procedure using $\mathrm{KOH}$. It was found that amounts of free fatty acids in liver homogenate after autolyzing for a few hours were lower in rats fed a low casein diet.
\end{abstract}

Free fatty acids are known to be a powerful uncoupling agent, and simultaneously to induce swelling in mitochondrial structure. ${ }^{1,2 !}$

Waterlow ${ }^{31}$ reported that $\mathrm{P}: \mathrm{O}$ ratio of liver homogenate from malnourished human infants was lower than that of normal subjects, and the reason for this phenomenon was considered that some uncoupling agent was produced from liver homogenate. He supposed this substance would be free fatty acids. Meanwhile, Porta and Hartroft ${ }^{4}$ reported that mitochondria were greatly enlarged in hepatocyte of a rat fed a low protein, high carbohydrate diet.

It was described in a previous report by the author" that energy efficiency of a low casein diet with respect to body protein maintenance decreased. In another report ${ }^{6)}$ it was described that the shape of mitochondria isolated from rats fed a low casein diet was diverse and the size was enlarged compared with that of normal rats. But, in spite of this phenomenon, respiratory control index of isolated mitochondria from rats fed a low casein diet was higher than that of normal rats.
In an attempt to elucidate these discrepancies, investigations on the free fatty acids in liver homogenate after autolyzing for a few hours were made, and the results obtained are discussed in connection with these phenomena.

For the measurement of free fatty acids in liver homogenate, the application of titra$\operatorname{tion}^{7,81}$ and colorimetric ${ }^{9,101}$ methods is very difficult. In consideration of the fact that degree of uncoupling and swelling of mitochondria by free fatty acids changes considerably by the kind of free fatty acids, ${ }^{11-131}$ it would be very convenient if composition and amount of free fatty acids are measured simultaneously by one method. So that, in this laboratory, a method using $3.0 \mathrm{KOH}$ for the purification of free fatty acids in the tissue was devised, and measurement was made by gaschromatography. Many examinations for the adequacy of this method were made, and are described below.

\section{MATERIALS AND METHODS}

Animals and diets. Male rats of the Donryu strain, 
weighing about $150 \mathrm{~g}$, were used. They were housed in individual cages in a temperature-controlled room at about $22^{\circ} \mathrm{C}$.

Composition of diets was the same as in the previous report. ${ }^{14}$ As in previous reports, ${ }^{6,14^{-17}}$ the low casein diet contained $4 \%$ casein, and the control diet 2506 casein. The salt and vitamin mixtures were made according to Harper. ${ }^{18,}$

Extraction of free fatty acids. Free fatty acids were extracted from the liver with all the other lipid components by Folch's method ${ }^{19}$ using chloroformmethanol $(2: 1)$.

Then, from the extracted lipids, phospholipids were removed by the method of Yasuda and Ohno ${ }^{20}$ using a silicic acid column.

Isolation and purification of free fatty acids. Free fatty acids were isolated and purified from lipids free of phospholipids by shaking with $3 \% \mathrm{KOH}$. The procedure is summarized in Fig. 1. First, lipids free of phospholipids were dissolved in $40 \mathrm{ml}$ of ether, and the solution was shaken with $15 \mathrm{ml}$ of $3 \% \mathrm{KOH}$ for exactly $2 \mathrm{~min}$. Lower phase was taken into a

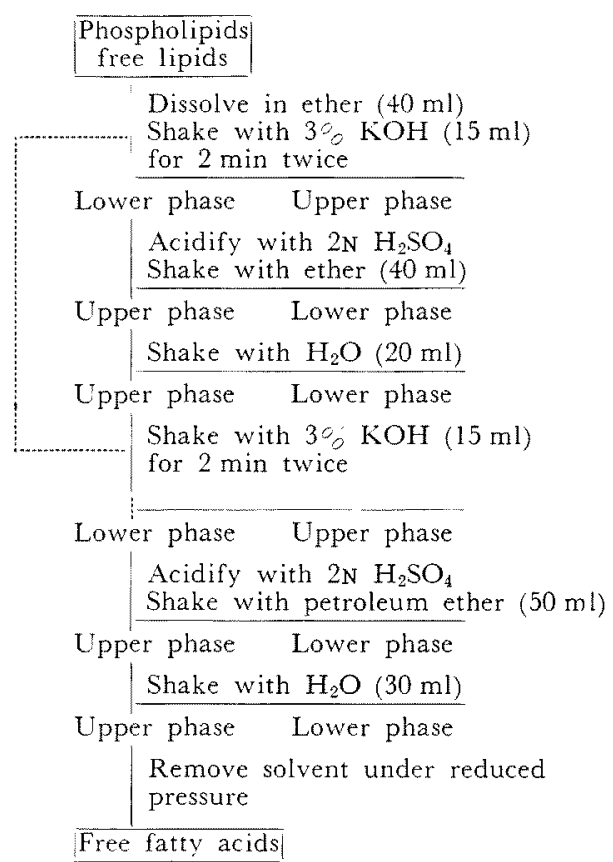

FIG. 1. Purification of Free Fatty Acids by Shaking with $30 \% \mathrm{KOH}$. beaker.* Etherial solution was shaken once more with $15 \mathrm{ml}$ of $39 \mathrm{KOH}$ for $2 \mathrm{~min}$, and the lower phase was taken again. The combined $\mathrm{KOH}$ solution was neutralyzed and acidified with $2 \mathrm{~N} \mathrm{H}_{2} \mathrm{SO}_{4}$ and shaken with $40 \mathrm{ml}$ of ether, and the lower phase was discarcled. Then, the upper phase was shaken with $20 \mathrm{ml}$ of distilled water, and the lower phase was discarded again. Thereafter, the treatments within dotted line in Fig. 1 were repeated twice more. Namely, these treatments were repeated three times totally.

Finally, after repeating these treatments three times, $\mathrm{KOH}$ solution was acidified with $2 \mathrm{~N} \mathrm{H}_{2} \mathrm{SO}_{4}$, and shaken with $50 \mathrm{ml}$ of petroleum ether instead of shaking with ether. After washing this petroleum ether solution with $30 \mathrm{ml}$ of distilled water, petroleum ether was removed under reduced pressure, and free fatty acids were obtained.

These treatments were all performed in a room whose temperature was not higher than $15^{\circ} \mathrm{C}$.

Quantitative analysis of free fatty acids by gas-liquid chromatography. Free fatty acids were methylated by $14 \% \mathrm{BF}_{3}$ in methanol as described in a previous report.17) Thereafter, to the fatty acid methyl esters, before gas-liquid chromatography, a fixed amount of heptadecanoic acid methyl ester was added. The analysis by gas-liquid chromatography was made as in the previous report, ${ }^{17}$ except that a flame ionization detector was used instead of a thermal conductivity detector, and nitrogen was used as carrier gas instead of helium.

The amount of each free fatty acid was calculated from the ratio of peak area of it to that of heptadecanoic acid added.**

Plan of experiments. The experiments were carried out in two phases as experiments 1 and 2 . In both experiments, rats were divided into two groups; and to one group, $4 \%$ casein diet was given, and to another, $250 \%$ casein diet. They were fed the test diets for 2 to 3 months.

In experiment 1, after rats were killed, liver was

* When the amount of free fatty acids was not minute, the solution was separated into three phases. In this case, lower two phases were taken into a beaker.

* The calculation was performed on the assumption that amount of heptadecanoic acid in free fatty acids would be very minute. 
homogenized with 4 fold volumes of medium containing $0.3 \mathrm{M}$ sucrose and $0.02 \mathrm{M}$ Tris buffer at $\mathrm{pH} 7.2$, using a teflon homogenizer. The homogenate obtained was incubated at $25^{\circ} \mathrm{C}$ for $2 \mathrm{hr}$, and thereafter, lipids were extracted.

In experiment 2, after rats were killed, liver was homogenized with $t$ fold volumes of distilled water using a tefion homogenizer, and lipids were extracted from the homogenate after incubating it at $30^{\circ} \mathrm{C}$ for $3 \mathrm{hr}$.

\section{RESULTS}

Examination of the adequacy of devised method for the quantitative estimation of free fatty acids At first, it was examined whether hydrolysis of ester bond of substances existing in etherial solution together with free fatty acids occurred by shaking with $3.0 \mathrm{KOH}$. Tripalmitin and cholesterol palmitate were used as the standard sample and were treated as described in Fig. 1 , and it was tested by gas-liquid chromatography whether there was any palmitic acid present in final free fatty acid fraction. Before gas-liquid chromatography, $0.3 \mathrm{mg}$ of heptadecanoic acid methyl ester was added. The results are shown in Fig. 2. It is seen from Fig. 2 that the peak of palmitic acid is very low compared with that of heptadecanoic acid added. It can be considered, from these results, that hydrolysis of ester bond would be very minute.

Next, recovery of free fatty acids by the procedure described in Fig. 1 was investigated. In this case, palmitic acid was used as free fatty acid. The results are shown in Table I. It can be seen from Table I that the recovery of free fatty acid was fairly constant, although it was considerably low. Accordingly, estimation of free fatty acids by this method would be considered semi-quantitative, and the amount of each free fatty acid was calculated in the following.

Table I. Recovery of Free FatTy ACID IN Purification Prccedure Lising Palmitic ACID AS FREe FatTy ACID

\begin{tabular}{lc}
\hline Lipid components in ether ${ }^{a,}$ & $\begin{array}{c}\text { Recovery } \\
\text { percent } \\
\left(0_{0}\right)\end{array}$ \\
\hline Palmitic acid (1 mg) & 56.9 \\
Palmitic acid (1 mg) + Tripalmitin (50 mg) & 63.1 \\
Palmitic acid (1 mg) + Tripalmitin (50 mg) & 59.4 \\
\hline
\end{tabular}

a) Lipid components dissolved in $40 \mathrm{ml}$ of ether before shaking with $3 \circ 0 \mathrm{KOH}$.

$b$; A fixed amount (1 mg) of heptadecanoic acid methyl ester was added before gas-liquid chromatography, and recovery percent was calculated from the ratio of peak area of palmitic acid to that of heptadecanoic acid added.

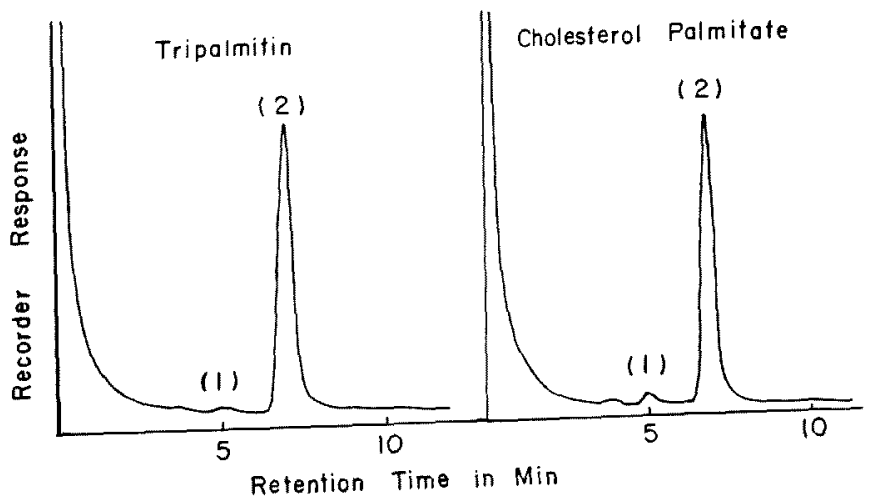

FIG. 2. Gaschromatogram of Free Fatty Acid Produced from Tripalmitin (50 mg) and Cholesterol Palmitate (100 mg) by Submitting to Free Fatty Acid Purification procedure. (1) Palmitic acid. (2) Heptadecanoic acid. 
Initial body weight, final body weight, liver weight and number of rats per group used in experiments 1 and 2

In Table II, initial body weight, final body weight, liver weight, and number of rats per group used in experiments 1 and 2 are shown. The body weight increase in experiment 1 was large, and the reason for this would be the extremely large food intake.

Composition and amount of free fatty acids from liver homogenate (made with medium containing $0.3 \mathrm{M}$ sucrose and $0.02 \mathrm{M}$ Tris buffer at $p H$ 7.2) after incubating for $2 \mathrm{hr}$ at $25^{\circ} \mathrm{C}$

Tables III and IV show composition and amount of free fatty acids from liver homogenate (made with medium containing $0.3 \mathrm{M}$ sucrose and $0.02 \mathrm{M}$ Tris buffer at $\mathrm{pH} 7.2$ ) after incubating at $25^{\circ} \mathrm{C}$ for $2 \mathrm{hr}$. It is seen from Table III that fatty acid composition differed considerably between two groups. Namely, palmitoleic, oleic and linoleic acids were lower in rats fed the low casein diet than in rats fed the high casein diet, and the reverse relationship was found in stearic and eicosatri- enoic acids. The differences in these fatty acids between two groups were statistically significant. The differences in amount of free fatty acids between two dietary groups were recognized also in some kinds of fatty acids, as seen from Table IV. Namely, amounts of palmitoleic, oleic and linoleic acids were lower in rats fed the low casein diet than in rats fed the high casein diet; and the differences in these fatty acids between two

Table II. InItial Body WeIght, Final Body Weight, Final Liver Weight and Number of Rats Per Group

$\begin{array}{ccccc}\text { Group } & \begin{array}{c}\text { Initial } \\ \text { body } \\ \text { weight } \\ (\mathrm{g})\end{array} & \begin{array}{c}\text { Final } \\ \text { body } \\ \text { weight } \\ (\mathrm{g})\end{array} & \begin{array}{c}\text { Final } \\ \text { liver } \\ \text { weight } \\ (\mathrm{g})\end{array} & \begin{array}{c}\text { Number } \\ \text { of rats } \\ \text { per }\end{array} \\ & \text { group }\end{array}$

\begin{tabular}{lcccc}
$4 \%$ Casein & $\left.154 \pm 16^{a}\right)$ & $187 \pm 31$ & $5.6 \pm 1.1$ & 5 \\
$25 \%$ Casein & $169 \pm 24$ & $403 \pm 34$ & $12.2 \pm 1.4$ & 5 \\
\multicolumn{5}{c}{ Experiment 2} \\
40 Casein & $147 \pm 17$ & $146 \pm 23$ & $3.8 \pm 0.6$ & 5 \\
$25 \%$ Casein & $142 \pm 25$ & $289 \pm 44$ & $8.1 \pm 1.1$ & 5 \\
\hline
\end{tabular}

a) Standard deviation.

Table III. Fatty Acid Composition of Free Fatty Acids from Homogenate (Made with Medium Containing 0.3 M Sucrose and 0.02 M Tris Buffer AT pH 7.2) AFter Autolyzing For $2 \mathrm{HR}$ at $25^{\circ} \mathrm{C}^{a}$

\begin{tabular}{lcccc}
\multicolumn{1}{c}{ Fatty acid } & $\begin{array}{c}4 \% \text { Casein } \\
(0)\end{array}$ & $\begin{array}{c}25 \% \text { Casein } \\
(\%)\end{array}$ & $\begin{array}{c}\text { Probability } \\
\text { difference by } t \text {-test }\end{array}$ \\
Myristic & $\left.(14: 0)^{d}\right)$ & $0.7 \pm 0.1 e)$ & $0.8 \pm 0.5$ & \\
Palmitic & $(16: 0)$ & $29.0 \pm 2.3$ & $27.4 \pm 2.4$ & \\
Palmitoleic & $(16: 1)$ & $3.6 \pm 0.4$ & $5.0 \pm 1.2$ & $P<0.05$ \\
Stearic & $(18: 0)$ & $19 . \pm \pm 0.4$ & $15.0 \pm 1.2$ & $P<0.01$ \\
Oleic & $(18: 1)$ & $18.4 \pm 1.7$ & $21.0 \pm 0.7$ & $P<0.02$ \\
Linoleic & $(18: 2)$ & $9.5 \pm 0.7$ & $12.2 \pm 1.4$ & $P<0.01$ \\
Linolenic & $(18: 3)$ & $1.9 \pm 0.7$ & $1.3 \pm 0.6$ & \\
Eicosatrienoic $(20: 3)$ & $2.2 \pm 0.4$ & $1.6 \pm 0.3$ & $P<0.02$ \\
Arachidonic & $(20: 4)$ & $15.3 \pm 1.9$ & $15.7 \pm 1.0$ & \\
\hline
\end{tabular}

a) The value was calculated on the basis that sum of fatty acids indicated in the table was regarded as $100 \%$.

b) Probability of difference between $40^{\circ}$ and $250^{\circ}$ casein diets groups.

c) The value was shown only where significant differences existed.

d. The numbers in parentheses represent the numbers of carbon and double bond in fatty acid.

e) Standard deviation. 
Table IV. Amounts of Free Fatty acids from Homogenate (Made with Medium Containing 0.3 M Sucrose and 0.02 M Tris Buffer at pH 7.2) AFTER AUTOLYZING FOR $2 \mathrm{HR}$ AT $25^{\circ} \mathrm{C}$ a

\begin{tabular}{llccc}
\multicolumn{2}{c}{ Fatty acid } & $\begin{array}{c}40 \text { Casein } \\
(\mu \mathrm{g} / \mathrm{g} \text { liver })\end{array}$ & $\begin{array}{c}250_{0} \text { Casein } \\
(\mu \mathrm{g} / \mathrm{g} \text { liver })\end{array}$ & $\begin{array}{c}\text { Probability } b, c) \text { of } \\
\text { difference by } t \text {-test }\end{array}$ \\
\hline Myristic & $(14: 0)^{d)}$ & $6 \pm 2$ & $9 \pm 4$ & \\
Palmitic & $(16: 0)$ & $255 \pm 103$ & $311 \pm 68$ & \\
Palmitoleic & $(16: 1)$ & $31 \pm 11$ & $55 \pm 8$ & $P<0.01$ \\
Stearic & $(18: 0)$ & $168 \pm 62$ & $169 \pm 32$ & $P<0.05$ \\
Oleic & $(18: 1)$ & $158 \pm 57$ & $237 \pm 38$ & $P<0.01$ \\
Linoleic & $(18: 2)$ & $81 \pm 26$ & $137 \pm 26$ & \\
Linolenic & $(18: 3)$ & $15 \pm 5$ & $14 \pm 5$ & \\
Eicosatrienoic $(20: 3)$ & $19 \pm 6$ & $18 \pm 5$ & \\
Arachidonic & $(20: 4)$ & $133 \pm 51$ & $176 \pm 23$ & \\
Total & & $866 \pm 313$ & $1125 \pm 172$ & \\
\hline
\end{tabular}

a) Calculated from the ratio of peak area of each fatty acid to that of heptadecanoic acid $z$ dded. The value was not corrected for recovery efficiency.

b) Probability of difference between 400 and $25^{\circ}$ casein diets groups.

c) The value was shown only where significant differences existed.

d: The numbers in parentheses represent the numbers of carbon and double bond in fatty acid.

e) Standard deviation.

Table V. Fatty Acid Composition of Free Fatty Acids from Homogenate (Made with Distilled Water) after Autolyzing for 3 hr at $30^{\circ} \mathrm{C} a$

\begin{tabular}{|c|c|c|c|c|}
\hline \multicolumn{2}{|c|}{ Fatty acid } & $\begin{array}{c}4 \% \text { Casein } \\
\left(O_{0}\right)\end{array}$ & $\begin{array}{c}250 \% \text { Casein } \\
(06)\end{array}$ & $\begin{array}{l}\text { Probability } y^{b} \text { of } \\
\text { difference by } t \text {-test }\end{array}$ \\
\hline Myristic & $(14: 0)^{d t}$ & $0.6 \pm 0.1^{\epsilon}$ & $0.5 \pm 0.2$ & \\
\hline Palmitic & $(16: 0)$ & $22.1 \pm 2.6$ & $21.2 \pm 1.7$ & \\
\hline Palmitoleic & $(16: 1)$ & $3.5 \pm 0.5$ & $4.2 \pm 0.6$ & \\
\hline Stearic & $(18: 0)$ & $12.0 \pm 1.1$ & $12.3 \pm 1.0$ & \\
\hline Oleic & $(18: 1)$ & $15.6 \pm 1.9$ & $15.7 \pm 1.4$ & \\
\hline Linoleic & $(18: 2)$ & $17.0 \pm 0.9$ & $17.2 \pm 0.9$ & \\
\hline Linolenic & $(18: 3)$ & $2.4 \pm 1.0$ & $1.8 \pm 0.7$ & \\
\hline Eicosatrienoic & $(20: 3)$ & $1.0 \pm 0.6$ & $0.9 \pm 0.7$ & \\
\hline Arachidonic & $(20: 4)$ & $25.7 \pm 4.3$ & $26.2 \pm 2.8$ & \\
\hline
\end{tabular}

a) The value was calculated on the basis that sum of fatty acids indicated in the table was regarded as 100,0 .

b) Probability of difference between $4 \%$ and $25 \%$ casein diets groups.

c) The value was shown only where significant differences existed.

d) The numbers in parentheses represent the numbers of carbon and double bond in fatty acid.

e) Standard deviation. 
Table VI. Amounts of Free Fatty Acids from Homogenate (Made with Distilled Water) after Autolyzing for 3 hr at $30^{\circ} \mathrm{C} a$

\begin{tabular}{lcccc}
\hline \multicolumn{2}{c}{ Fatty acid } & $\begin{array}{c}40 \text { Casein } \\
(\mu \mathrm{g} / \mathrm{g} \text { liver })\end{array}$ & $\begin{array}{c}250 \text { Casein } \\
(\mu \mathrm{g} / \mathrm{g} \text { liver })\end{array}$ & $\begin{array}{c}\text { Probability } b, a) \text { of } \\
\text { difference by } t \text {-test }\end{array}$ \\
\hline Myristic & $(14: 0)^{d)}$ & $15 \pm 5 e)$ & $16 \pm 6$ & \\
Palmitic & $(16: 0)$ & $515 \pm 84$ & $668 \pm 85$ & $P<0.05$ \\
Palmitoleic & $(16: 1)$ & $83 \pm 18$ & $132 \pm 26$ & $P<0.01$ \\
Stearic & $(18: 0)$ & $280 \pm 36$ & $386 \pm 35$ & $P<0.01$ \\
Oleic & $(18: 1)$ & $368 \pm 85$ & $496 \pm 64$ & $P<0.05$ \\
Linoleic & $(18: 2)$ & $398 \pm 68$ & $542 \pm 63$ & $P<0.01$ \\
Linolenic & $(18: 3)$ & $55 \pm 20$ & $57 \pm 18$ & \\
Eicosatrienoic $(20: 3)$ & $23 \pm 13$ & $26 \pm 20$ & \\
Arachidonic & $(20: 4)$ & $599 \pm 125$ & $824 \pm 96$ & $P<0.02$ \\
Total & & $2336 \pm 325$ & $3146 \pm 247$ & $P<0.01$
\end{tabular}

a) Calculated from the ratio of peak area of each fatty acid to that of heptadecanoic acid added. The value was not corrected for recovery efficiency.

b) Probability of difference between $4 \%$ and $25 \%$ casein diets groups.

o) The value was shown only where significant differences existed.

d) The numbers in parentheses represent the numbers of carbon and double bond in fatty acid.

e) Standard deviation.

groups were statistically significant. The difference in total amount of free fatty acids between two groups was not statistically significant.

Composition and amount of free fatty acids from liver homogenate (made with water) after incubating for $3 \mathrm{hr}$ at $30^{\circ} \mathrm{C}$

In Tables V and VI, composition and amount of free fatty acids from liver homogenate (made with water) after incubating for $3 \mathrm{hr}$ at $30^{\circ} \mathrm{C}$ are shown. It is seen from Table $\mathrm{V}$ that fatty acid composition was almost identical in both groups. But the amount of each free fatty acid was lower in rats fed the low casein diet than in rats fed the high casein diet, and the difference in each fatty acid between two groups was statistically significant in almost all cases, as seen from Table VI.

\section{DISCUSSION}

Measurement of free fatty acids in the organ such as liver by hitherto used methods, is very difficult. Accordingly, the method presented in this paper, although it is not made perfect yet, can be considered usable as judged from the hydrolysis and recovery experiments. It can be used under some limited conditions, though precautions should be taken on the following points. (1) Amount of free fatty acids present should not be large. If large amount of free fatty acids are present, some hydrolysis of ester bonds of contaminating substances occurs. (2) Alkaline solutions of free fatty acids should not be kept too long. If they are kept for several hours, some hydrolysis of ester bonds of contaminating substances occurs. (3) Temperature of the room in which experiments are performed should be kept below $15^{\circ} \mathrm{C}$. Attentions should be paid on these points in carrying out the procedure.

The amount of free fatty acids present after autolysis of homogenate was regarded as the difference between production and disappearance of free fatty acids by various pathways. Actions of various phospholipases, lysophospholipases and lipases are considered to be free fatty acids producing reactions. Break- 
down of fatty acids by the fatty acid oxidation cycle and esterification of fatty acyl CoA by lipid synthesizing enzymes, result in disappearance of free fatty acids.

In the present experiments, on incubating the liver homogenate, there was a tendency that the amount of free fatty acids was higher in rats fed the high casein diet than in those fed the low casein diet regardless of the homogenizing medium used. The phenomenon that respiratory control index of liver mitochondria was higher in rats fed a low casein diet than in those fed a high casein diet might have some relationship with the results of the present experiments that the amount of free fatty acids in liver homogenate was lower in rats fed the low casein diet.

In the case of homogenate made with a medium containing $0.3 \mathrm{M}$ sucrose and $0.02 \mathrm{M}$ Tris buffer, cell particles such as mitochondria and lysosomes would not be destroyed. But, in the case of homogenate made with water, these particles are destroyed, and many lipid hydrolyzing enzymes in these particles would operate actively. When the amounts of free fatty acids produced are compared in these two cases, they were smaller in rats fed a low casein diet in both cases. This means that after the destruction of particles, amounts of free fatty acids produced by destructed particles were also smaller in rats fed a low casein diet.

As a next step, it is necessary to make clear whether the production of free fatty acids is inhibited in purified mitochondria of rats fed a low casein diet, and if it is inhibited as in the case of homogenate, it would be the reason why respiratory control of $\mathrm{mi}$ tochondria is preserved. Since other cell particles as lysosomes contain many lipid hydrolyzing enzymes, it is necessary to use mitochondria completely freed from these particles. Purification of mitochondria is under investigation now in our laboratory.

It can be considered, from the results of the present experiments, that the morphological change of mitochondria resulting from a low casein diet $t^{61}$ would be caused by factors other than free fatty acids. Moreover, in our recent experiments, ${ }^{21}$ when mitochondria were isolated from rats fed a low casein diet using a medium containing considerably large amount of bovine serum albumin, some morphological changes were still noticed.

Waterlow $^{3}$ described that in malnourished children, $\mathrm{P}: \mathrm{O}$ ratio of liver homogenate was lower than that of normal. Since the liver he used was very fatty, lipase might have acted on neutral fat, and then the amount of free fatty acids produced would be large. In our experiments, no symptoms of fatty liver were noticed in rats fed the low casein diet, and actually, as in a previous report, liver fat content was not high in rats fed a $40^{\circ}$ casein diet. Although nutrients other than protein might have been deficient in Waterlow's experiments, the difference between his results and ours would largely owe to liver fat content.

\section{REFERENCES}

1) A. L. Lehninger and L. F. Remmert, $J$. Biol. Chem., 234, 2459 (1959).

2) L. Wojtczak and A. L. Lehninger, Biochim. Biophys. Acta, 51, 442 (1961).

3) J. C. Waterlow, Proc. Royal Soc. London, Ser. B., 155, 96 (1961).

4) E. A. Porta and W.S. Hartroft, Am. J. Clin. Nutrition, 23, 447 (1970).

5) N. Harada and K. Ashida, Agr. Biol. Chem., 28, 56 (1964).

6) N. Harada, J. Nutrition, 93, 263 (1967).

7) V.P. Dole, J. Clin. Invest., 35, 150 (1956).

8) V.P. Dole and H. Meinertz, J. Biol. Chem., 235, 2595 (1960).

9) W. G. Duncombe, Biochem., J., 88, 7 (1963).

10) K. Itaya and M. Ui, J. Lipid. Res., 6, 16 (1965).

11) B. C. Pressman and H. A. Lardy, Biochim. Biophys. Acta, 21, 458 (1956).

12) P. Borst, J.A. Loos, E.J. Christ and E. C. Slater, ibid., 62, 509 (1962).

13) J. Zborowski and L. Wojtczak, ibid., 70, 596 
(1963).

14) N. Harada, M. Ishibashi, T. Sato and Y. Hamazima, J. Nutrition, 100, 1455 (1970).

15) N. Harada and S. Mogi, Agr. Biol. Chem., 30, 274 (1966).

16) N. Harada and T. Suzuki, ibid., 32, 340 (1968).

17) N. Harada, M. Kurahashi and M. Haga, ibid., 33, 168 (1969).
18) A. E. Harper, $J$. Nutrition, 68, 405 (1959).

19) J. Folch, M. Lees and G. H. Sloanestanley, $J$. Biol. Chem., 226, 497 (1957).

20) M. Yasuda and K. Ohno, "Tanpakushitsu Kakusan Koso," A Separate Volume, Seibutsukagaku Jikkenho, Vol. VII, Kyoritsu Shuppan Co., Tokyo, 1967, p. 84.

21) T. Sato and N. Harada (unpublished data). 